\title{
Functional characterization of a microbial aquaglyceroporin
}

UMR CNRS, Interactions Cellulaires et Moléculaires, Equipe Canaux et Récepteurs Membranaires, Université de Rennes 1, Campus de Beaulieu, 35042 Rennes cedex, France

\author{
Alexandrine Froger, Jean-Paul Rolland, Patrick Bron, Valérie Lagrée, \\ Françoise Le Cahérec, Stéphane Deschamps, Jean-François Hubert, \\ Isabelle Pellerin, Daniel Thomas and Christian Delamarche
}

Author for correspondence: Christian Delamarche. Tel.: +332992861 22. Fax: +33299281477. e-mail: christian.delamarche@univ-rennes1.fr

\begin{abstract}
The major intrinsic proteins (MIPs) constitute a widespread membrane channel family essential for osmotic cell equilibrium. The MIPs can be classified into three functional subgroups: aquaporins, glycerol facilitators and aquaglyceroporins. Bacterial MIP genes have been identified in archaea as well as in Gram-positive and Gram-negative eubacteria. However, with the exception of Escherichia coli, most bacterial MIPs have been analysed by sequence homology. Since no MIP has yet been functionally characterized in Gram-positive bacteria, we have studied one of these members from Lactococcus lactis. This MIP is shown to be permeable to glycerol, like $E$. coli GlpF, and to water, like E. coli AqpZ. This is the first characterization of a microbial MIP that has a mixed function. This result provides important insights to reconstruct the evolutionary history of the MIP family and to elucidate the molecular pathway of water and other solutes in these channels.
\end{abstract}

Keywords: glycerol transport, water transport, Lactococcus lactis

\section{INTRODUCTION}

The major intrinsic protein (MIPs) constitute a widespread membrane channel family, essential for osmotic cell equilibrium, that has been identified in bacteria, fungi, protozoa, insects, plants and mammals (Preston et al., 1992; Maurel, 1997; Froger et al., 1998; Agre et al., 1998; Borgnia et al., 1999a). The MIPs can be classified into three functional subgroups: aquaporins (AQPs), glycerol facilitators (GlpFs) and aquaglyceroporins.

Aquaporins are highly specific for water. The most studied aquaporin, AQP1, has been analysed by electron crystallography and a three-dimensional reconstruction at $0 \cdot 38-0 \cdot 4 \mathrm{~nm}$ resolution has been obtained (Ren et al., 2000; Murata et al., 2000). AQP1 is a homotetramer of $28 \mathrm{kDa}$ subunits, each containing six transmembrane helices.

Glycerol facilitators are permeable to glycerol or small uncharged molecules. The crystal structure of the E. coli glycerol facilitator $(\mathrm{GlpF})$ has been resolved at $0 \cdot 22 \mathrm{~nm}$ by X-ray crystallography (Fu et al., 2000). GlpF crystallizes as a symmetric arrangement of four channels with three glycerol molecules in each.

Abbreviation: MIP, major intrinsic protein.
As expected from their sequence similarities, AQPs and GlpFs exhibit a similar structural organization. However, differences in the channel-lining side chains and the residues at the narrowest parts of the channels create two different environments which should be responsible for the channel selectivity.

Aquaglyceroporins, such as AQP3, AQP7and AQP9, describe a new class of water channels which are also permeable to glycerol, but to a lesser degree than GlpF (Echevarria et al., 1994; Ishibashi et al., 1994; Ma et al., 1994; Ishibashi et al., 1997; Kuriyama et al., 1997; Ishibashi \& Sasaki, 1998; Tsukagushi et al., 1998). Aquaglyceroporins are of particular interest for the investigation of the molecular basis of selectivity for both water and solutes and to address the question of a distinct molecular mechanism for such mixed channels.

Using statistical sequence analysis we have pointed out that only few key residues could distinguish aquaporins from glycerol facilitators and thus could contribute to their functional properties (Froger et al., 1998; Delamarche, 2000). This finding was supported by an experimental approach where a substitution of two key residues in an aquaporin abolished water transfer and conferred selectivity to glycerol associated with monomerization of the protein (Lagrée et al., 1999).

To bring new insights to elucidating the determination 


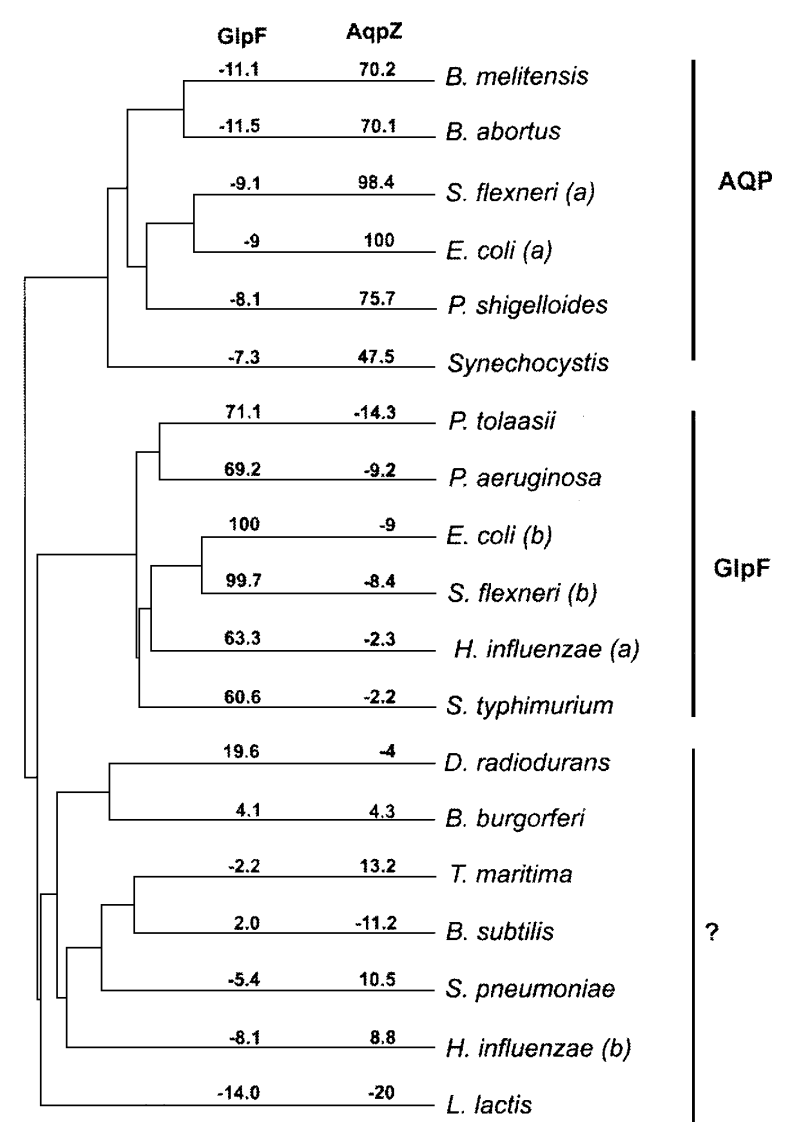

Fig. 1. Sequence comparison analysis. Sequences were extracted from the EMBL and SWISS-PROT databases. Brucella melitensis (accession no. AAF73105), Brucella abortus (AAF36396), Shigella flexneri (O68874, a; P31140, b), E. coli* (P48838, a; P11244, b), Plesiomonas shigelloides (Baa85015), Synechocystis sp.* (P73809), Pseudomonas tolaasii (O83003), Pseudomonas aeruginosa (Q51389), Haemophilus influenzae* (P44826, a; O86231, b), Salmonella typhimurium (P37451), Deinococcus radiodurans* (Aaf11483), Borrelia burgorferi (O51256), Thermotoga maritima (AE001795), Bacillus subtilis* (P18156), Streptococcus pneumoniae (P52281) and L. lactis (P22094). Asterisks indicate genomes that have been entirely sequenced. The similarity scores with $E$. coli GlpF and AqpZ are presented above each branch.

of MIP specificity, it is of primary importance to analyse the structural and functional properties of homologues, chimaeras, mutants and particularly members bearing unconventional functional properties. Presently, only a few microbial MIPs have been studied functionally (Maurel et al., 1994; Calamita et al., 1995, 1998; Delamarche et al., 1999; Borgnia et al., 1999b, Calamita, 2000) and most microbial members of the MIP family have been functionally classified by sequence homology (Hohmann et al., 2000). Thus, the physiological roles of prokaryote MIP channels are still largely undefined.

A multiple sequence alignment analysis conducted between bacterial members of the MIP family separates the sequences into three major clusters, one corresponding to aquaporins, one to glycerol facilitators and a third to a subgroup not yet correlated to a defined function, suggesting that some microbial MIPs bear unorthodox functional properties (Fig. 1).

A MIP gene (accession no. P22094) from the Grampositive bacterium, Lactococcus lactis, has been cloned (Nardi et al., 1991; Mayo et al., 1991). Here we have studied glycerol and water transport properties of this L. lactis MIP in two heterologous expression systems: a bacterial one, an E. coli aqpZ $Z^{-} g l p F^{-}$strain, and a eukaryotic one, Xenopus laevis oocytes. We demonstrate that the L. lactis MIP transports both glycerol and water and, thus, is the first microbial MIP described that has a mixed function.

\section{METHODS}

Bacterial strains and plasmids. The bacterial strains and plasmids used in this study are listed in Table 1. The ORF1 coding region of L. lactis was amplified by PCR from plasmid pTIL2 (Nardi et al., 1991). The resulting PCR band (952 bp) was subcloned into the BamHI and BglII sites of pUC18 and $\mathrm{pX} \beta \mathrm{G}$-ev1 to give pUC-Llac and pSP-Llac, respectively. In the constructs pUC-glpF and pUC-Llac (Table 1), the expression of the cloned genes is under the control of the lactose promoter.

Growth analysis. Bacterial strains were routinely plated on LB or M9 agar medium in the presence of $50 \mu \mathrm{g}$ ampicillin $\mathrm{ml}^{-1}$ (Sambrook et al., 1989). For overnight liquid cultures, bacterial strains were grown aerobically at $30{ }^{\circ} \mathrm{C}$ in $\mathrm{M} 9$ modified minimal medium (M9: $0 \cdot 2 \%$ Casamino acids, $100 \mu \mathrm{g}$ ampicillin $\mathrm{ml}^{-1}$ ) supplemented with maltose $(10 \mathrm{mM})$. Growth was monitored by measuring the $\mathrm{OD}_{600}$ of the cultures in $\mathrm{M} 9$ modified medium supplemented with glycerol $(2 \mathrm{mM})$.

Glycerol transport assays in E. coli. Glycerol transport assays were performed as described by Sweet et al. (1990) with the following modifications. Bacteria were grown in M9 modified medium containing maltose $(10 \mathrm{mM})$ at $30^{\circ} \mathrm{C}$ to an $\mathrm{OD}_{600}$ of $0 \cdot 3$. Cells were harvested, pelleted, washed twice with M9 and then resuspended in M9. Assays were performed at room temperature with $6 \times 10^{8}$ cells at a final volume of $500 \mu \mathrm{l}$ M9 containing $0.3 \mu \mathrm{M}\left[\mathrm{U}_{-}{ }^{14} \mathrm{C}\right]$ glycerol (final activity $5.92 \mathrm{Gbq}$ $\mathrm{mmol}^{-1}$; Amersham). After $1 \mathrm{~min}$ of incubation, cells were vacuum-filtered through $0.45 \mu \mathrm{m}$ cellulose nitrate membrane filters (Whatman), washed with $2 \mathrm{ml}$ cold M9 and the radioactivity was counted.

Glycerol transport assays in Xenopus oocytes. Plasmids pSPglpF, pSP-aqpZ and pSP-Llac were linearized with $\mathrm{XbaI}$ and transcribed with T3 RNA polymerase by means of the mCAP cRNA capping kit (Stratagene). Stage VI Xenopus oocytes were microinjected with $40 \mathrm{nl}$ water for controls or with in vitro mRNA transcripts $\left(1 \mu \mathrm{g} \mu^{-1}\right)$ and incubated in OR2 buffer (Le Cahérec et al., 1996) for $48-72 \mathrm{~h}$ at $16-18{ }^{\circ} \mathrm{C}$.

At 48-72 $\mathrm{h}$ after microinjection, the oocytes were incubated in OR2/2 supplemented with $85 \mathrm{mM}$ glycerol to adjust the osmolarity to $176 \operatorname{mosM}$ and with $\left[\mathrm{U}-{ }^{14} \mathrm{C}\right]$ glycerol (final activity $0.3 \mathrm{Mbq} \mathrm{ml}^{-1}$ ). After $10 \mathrm{~min}$, the oocytes were rapidly rinsed four times in $2 \mathrm{ml}$ ice-cold solution (half strength solution of OR2 supplemented with $85 \mathrm{mM}$ glycerol) and lysed in $10 \%$ SDS at room temperature. Radioactivity was measured by using a liquid scintillation counter.

Swelling of Xenopus oocytes. Osmotic water permeability $\left(P_{\mathrm{f}}\right)$ was measured from the time course of oocytes swelling in 
Table 1. Terminology of bacterial strains and plasmids used in this paper

\begin{tabular}{|c|c|c|}
\hline Strain or plasmid & Description & Source or reference \\
\hline \multicolumn{3}{|l|}{ E. coli $\mathrm{K}-12$ derivatives } \\
\hline JM103 & $\begin{array}{l}\Delta(\text { lac-pro }) \text { thi strA supE end } A \text { sbcB15 hsdR } 4\left(\mathrm{~F}^{\prime} \text { traD } 36 \text { pro } A B\right. \\
\left.\text { lacl }^{\mathrm{a}} \Delta \text { lacZM } 15\right)\end{array}$ & Messing et al. (1981) \\
\hline GD236 & JM103 $g l p F^{-}$ & Sweet et al. (1990) \\
\hline MM294 & $\mathrm{F}^{-}$endA1 hsdR17 $\left(\mathrm{r}_{\mathrm{K}}^{-}, \mathrm{m}_{\mathrm{K}}^{-}\right)$supE44 thi-1 & Meselson \& Yuan (1968) \\
\hline SK46 & MM294 $g l p F^{-} a q p Z^{-} ; \mathrm{Km}^{\mathrm{r}} \mathrm{Sm}^{\mathrm{r}}$ & G. Calamita, unpublished \\
\hline \multicolumn{3}{|l|}{ Plasmids } \\
\hline pUC18 & Cloning vector; $\mathrm{Ap}^{\mathrm{r}}$ & Yanisch-Perron et al. (1985) \\
\hline pUC-glpF & $g l p F$ in $\mathrm{pUC18}$ & Lagrée et al. (1998) \\
\hline pUC-Llac & L. lactis MIP in pUC18 & This study \\
\hline $\mathrm{pX} \beta \mathrm{G}-\mathrm{ev} 1$ & Cloning vector $\mathrm{Ap}^{\mathrm{r}}$ & Preston et al. (1992) \\
\hline pSP-glpF & $g l p F$ in $\mathrm{pX} \beta \mathrm{G}-\mathrm{ev} 1$ & Lagrée et al. (1998) \\
\hline pSP-Llac & L. lactis MIP in $\mathrm{pX} \beta \mathrm{G}-\mathrm{ev} 1$ & This study \\
\hline SP-aqpZ & $\mathrm{pX} \beta \mathrm{G}$-aqpZ $=a q p Z$ in $\mathrm{pX} \beta \mathrm{G}$-ev1 & Calamita et al. (1995) \\
\hline
\end{tabular}

response to a threefold dilution of extracellular OR2. To calculate the activation energy $\left(E_{\mathrm{a}}\right)$ the $P_{\mathrm{f}}$ was measured at three different temperatures, 10,20 and $30^{\circ} \mathrm{C}$, as described previously (Le Cahérec et al., 1996).

Cryoelectron microscopy. E. coli SK46, either with or without the plasmid pUC-Llac, was grown overnight in M9 modified minimal medium supplemented with maltose $(10 \mathrm{mM})$. These cultures were diluted and grown at $37^{\circ} \mathrm{C}$ until the exponential phase $\left(\mathrm{OD}_{600}=0.8\right)$ in $\mathrm{M} 9$ containing maltose. The bacteria were then pelleted rapidly and resuspended in M9 (240 mosM) at room temperature. A $2.5 \mu \mathrm{l}$ drop of the cell suspension was placed directly on a copper grid coated with a thin carbon film, upon which osmotic challenges were performed. Osmotic upshocks were induced by rapidly mixing $2.5 \mu \mathrm{l}$ of a $1.2 \mathrm{M}$ sucrose-M9 solution with the cell suspension on the grid (final osmolarity $1000 \operatorname{mos} \mathrm{M}$ ). After $10 \mathrm{~s}$ the grid was briefly blotted with filter paper and plunged into liquid ethane held at liquid nitrogen temperature. Specimens were examined at $-170{ }^{\circ} \mathrm{C}$ in a Philips CM12 microscope with a Gatan model 626 cryoholder (Delamarche et al., 1999). Micrographs were recorded on Kodak SO 163 film under low-dose conditions at a nominal magnification of 6300 .

Sequence analysis. The MIP sequences, retrieved from the EMBL and SWISS-PROT databases, were aligned with PILEUP or CLUSTAL W (Devereux et al., 1984; Thompson et al., 1994). Computing was performed using Infobiogen resources (http://www.infobiogen.fr). A score $(i, j)$ is the sum of the elementary scores between two aligned sequences $i$ and $j$, using the BLosum matrix (Henikoff \& Henikoff, 1992). By default, a score of 8 is attributed for the gap insertions. The similarity scores presented in Fig. 1 were calculated at Infobiogen with the program EDTALN: percentage score $(i, j)$ $=100 *\{\operatorname{score}(i, j) / \max [\operatorname{score}(i, i)$, score $(j, j)]\}$.

\section{RESULTS}

\section{Expression of $L$. lactis MIP in E. coli KO strains}

Different glycerol concentrations between 0.5 and $5 \mathrm{mM}$ were used to determine the optimal concentration of glycerol required to distinguish the growth rates of strain GD236 $\left(g l p F^{-}\right)$expressing a glycerol channel or not. A concentration of $2 \mathrm{mM}$ glycerol increased the
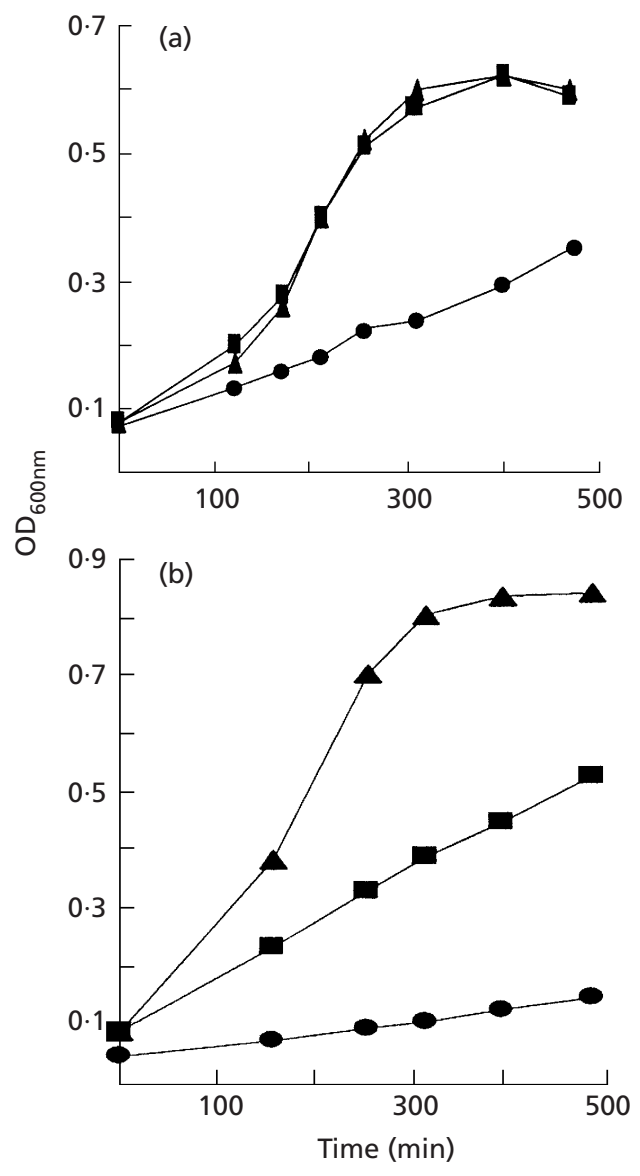

Fig. 2. Complementation experiments in $M 9$ modified medium supplemented with glycerol $(2 \mathrm{mM})$. Growth curve of $E$. coli strains GD236 $\left(g / p F^{-}\right)$(a) and SK46 $\left(g / p F^{-}\right.$aqpZ $)$(b), transformed with pUC18 $(\mathbf{O})$, pUC-glpF $(\boldsymbol{\square})$ or pUC-Llac $(\boldsymbol{\Delta})$.

growth rate of the mutant strain transformed with pUCglpF (Fig. 2a). A similar result was obtained with the mutant strain transformed with pUC-Llac. These 


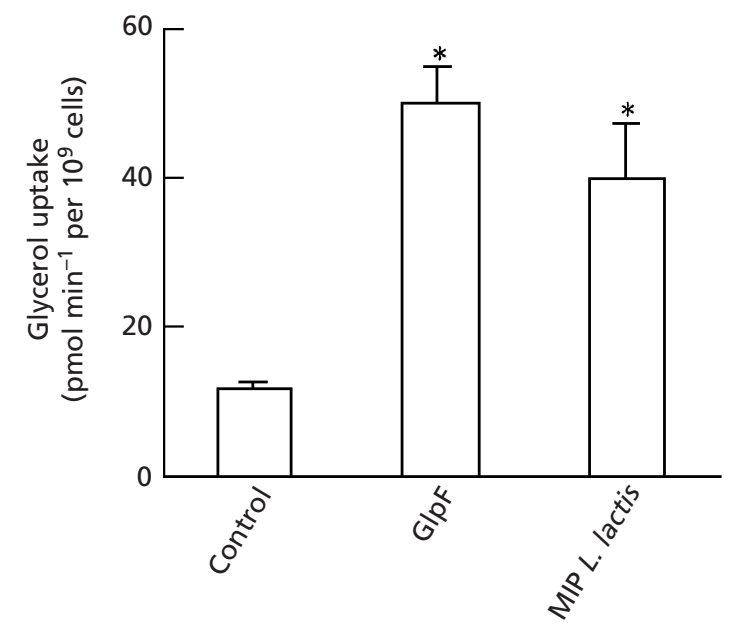

Fig. 3. Glycerol uptake in $E$. coli strain GD236 (g/pF-) transformed with pUC18 (control), pUC-glpF (GlpF) and pUCLlac (MIP L. lactis). The values represent a mean of three measurements for three independent experiments $( \pm \mathrm{SD}) \quad\left({ }^{*} P<\right.$ 0.001 versus control).

growth curves are similar to those obtained with the wild-type strain JM103 in the same medium (data not shown). As expected, the control cells, strain GD236 $\left(g l p F^{-}\right)$, reached the same final density as the cells expressing a glycerol channel, but at a slower rate. Strain SK46 $\left(g l p F^{-} a q p Z^{-}\right)$was not able to grow using only $2 \mathrm{mM}$ glycerol as carbon source (Fig. 2b). The expression of E. coli GlpF, from pUC-glpF, stimulated the growth of this strain, but did not restore the growth level obtained when expressed in strain GD236. Comparatively, the expression of L. lactis MIP had the same effect on the growth of SK46 as did pUC-Llac or pUCglpF on GD236 (Fig. 2a). Thus, pUC-Llac complements the double mutation $\left(g l p F^{-} a q p Z^{-}\right)$in E. coli and we suggest that L. lactis MIP is involved in glycerol transport as well as water transport.

\section{L. lactis MIP is a glycerol facilitator}

E. coli strain GD236 $\left(g l p F^{-}\right)$transformed with vector pUC18 or with pUC-glpF was used in assays of glycerol uptake under steady-state conditions. In the absence of GlpF there was little uptake of glycerol (Fig. 3). pUC$\mathrm{glpF}$ complemented the transport defect and resulted in a final glycerol uptake level four- to fivefold higher than the control level. pUC-Llac had the same effect on glycerol uptake. The $K_{\mathrm{m}}$ was found to be $20 \mu \mathrm{M}$ glycerol for strain GD236 expressing the L. lactis MIP, a value close to $22 \cdot 3 \mu \mathrm{M}$ for the wild-type strain JM103 (data not shown). This is consistent with glycerol transport catalysed by L. lactis MIP expressed in E. coli.

Expression of heterologous proteins into Xenopus oocytes was used as a reference system for the functional studies of MIPs. cRNAs corresponding to L. lactis MIP and E. coli GlpF were injected into Xenopus oocytes and

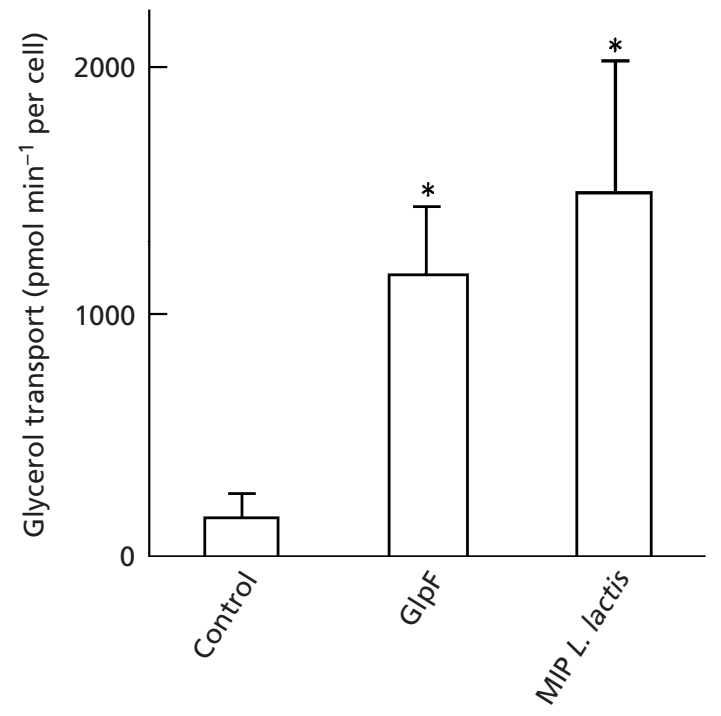

Fig. 4. Glycerol transport in Xenopus oocytes. $\left[{ }^{14} \mathrm{C}\right]$ Glycerol uptake in oocytes injected with water (control), E. coli GlpF and $L$. lactis MIP CRNAs $(20$ measurements \pm SD) $(* P<0.01$ versus control).

the cells were assessed for permeability to glycerol. The glycerol uptake $\left(P_{\mathrm{gly}}\right)$ of oocytes was measured in the presence of $\left[{ }^{14} \mathrm{C}\right] \mathrm{glycerol}$. Oocytes injected with L. lactis and E. coli MIP cRNA showed a large increase in $\left[{ }^{14} \mathrm{C}\right]$ glycerol uptake compared to control oocytes. The glycerol uptake of oocytes expressing L. lactis MIP was 1484 pmol per min per cell and 1149 pmol per min per cell for oocytes expressing E. coli GlpF (Fig. 4). The corresponding calculated $P_{\text {gly }}$ values were $6 \cdot 2 \times 10^{-6} \mathrm{~cm} \mathrm{~s}^{-1}$ for oocytes expressing L. lactis MIP and $4.8 \times 10^{-6} \mathrm{~cm} \mathrm{~s}^{-1}$ for oocytes expressing E. coli GlpF. Thus, the L. lactis MIP is a glycerol facilitator imparting permeability to glycerol equivalent to E. coli GlpF.

\section{L. lactis MIP is a water channel}

E. coli strain SK46 ( $\left.g l p F^{-} a q p Z^{-}\right)$containing plasmid pUC-Llac was subjected to a hyperosmotic shock and observed by cryoelectron microscopy. E. coli cells expressing the L. lactis MIP showed retraction of the cytoplasm, thus forming plasmolysis spaces (Fig. 5b). Under the same conditions no shrinkage was observed in control cells (SK46) lacking the MIP plasmid (Fig. 5a). These results demonstrate that L. lactis MIP is responsible for the outward direct water flux and, thus, constitutes an efficient water channel.

The permeability to water of L. lactis MIP was calculated by measuring the swelling of cRNA-injected oocytes submitted to hypotonic shock. The $P_{\mathrm{f}}$ value of $L$. lactis MIP cRNA-injected oocytes was 10-fold higher than the $P_{\mathrm{f}}$ of water-injected oocytes or oocytes expressing E. coli GlpF and had the same magnitude as 

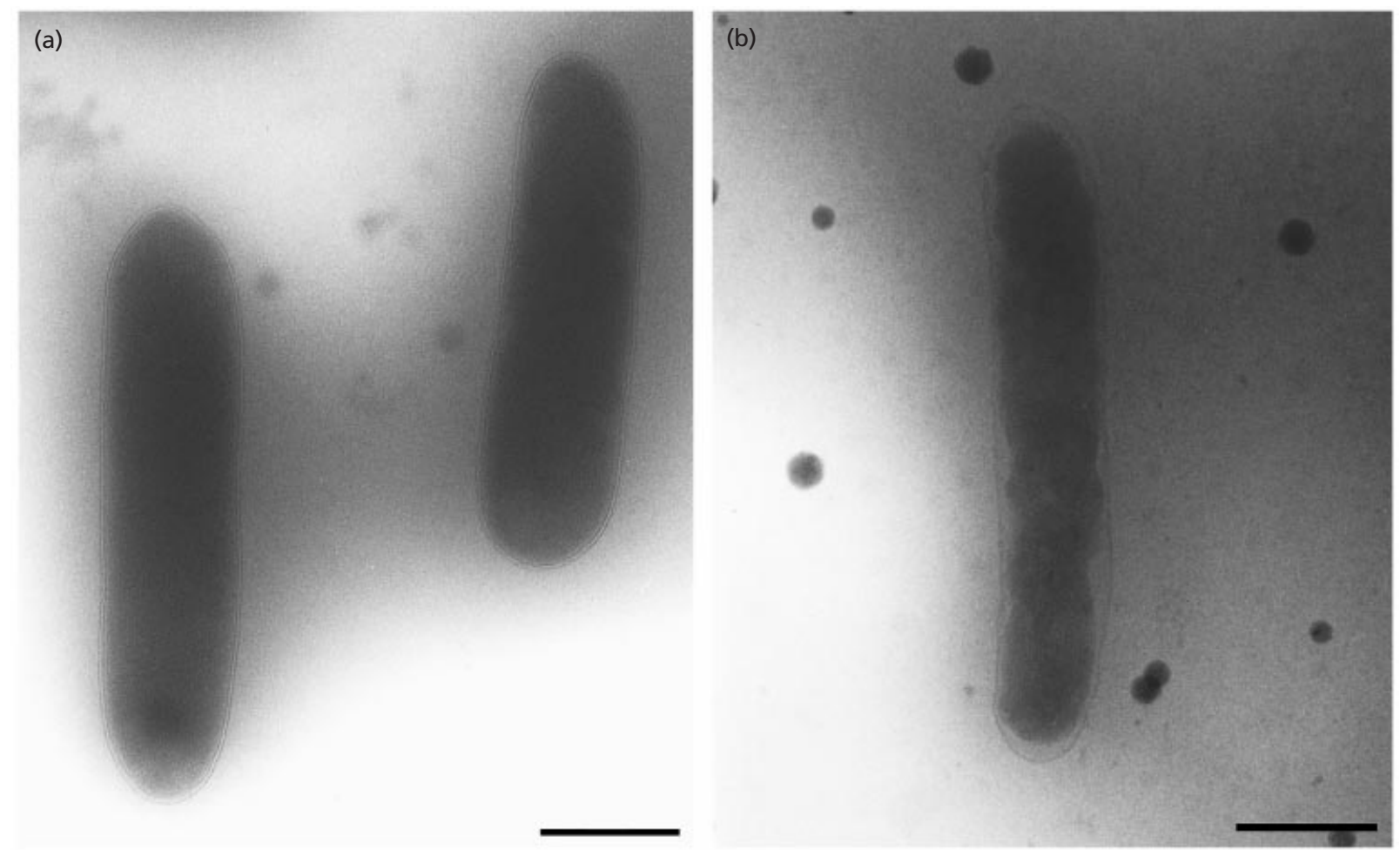

Fig. 5. Cryoelectron micrographs of $E$. coli SK46 following a 10 s hyperosmotic shock. (a) $E$. coli SK46, an AqpZ ${ }^{-}$and $\mathrm{GlpF}^{-}$ null mutant. (b) E. coli strain SK46 expressing L. lactis MIP. Bars, $1 \mu \mathrm{m}$.

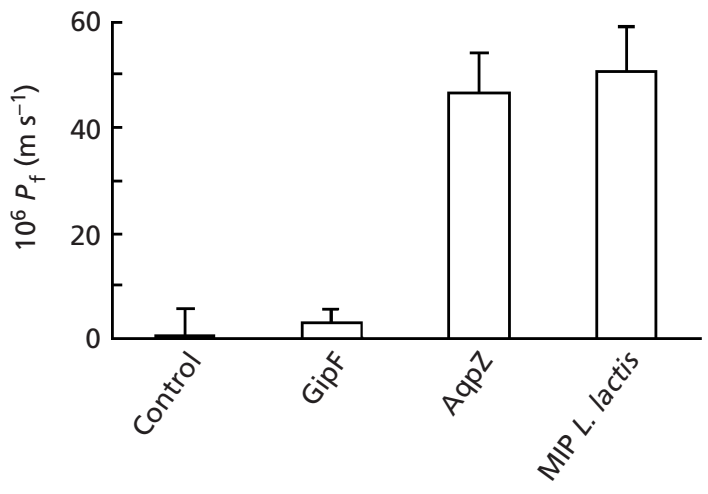

Fig. 6. Osmotic water permeability of Xenopus oocytes injected with water (control), E. coli GlpF, E. coli AqpZ and L. lactis MIP cRNAs (20 measurements \pm SD).

oocytes expressing E. coli AqpZ (Fig. 6). Incubation of cRNA-injected oocytes in $\mathrm{HgCl}_{2}$ did not lower the $P_{\mathrm{f}}$ value (data not shown), a result consistent with the absence of cysteine in L. lactis MIP. The Arrhenius activation energy $\left(E_{\mathrm{a}}\right)$ was calculated from $P_{\mathrm{f}}$ values obtained by monitoring oocyte swelling at 10, 20 and $30{ }^{\circ} \mathrm{C}$ (data not shown). The $E_{\mathrm{a}}$ was $4.76 \mathrm{kcal} \mathrm{mol}^{-1}$, a value within the range expected for a typical aquaporin and higher than that of control oocytes.

\section{DISCUSSION}

One way to understand the structural/functional relationships in MIPs resides in the resolution of their three-dimensional structure at the atomic level. However, such structural studies are limited by the need to produce significant amounts of purified wild-type and mutant proteins. A promising alternative resides in gathering knowledge about the MIP family by searching for new members, analysing their functions and the effect of selected mutations. In this paper we present the functional characterization of a novel microbial MIP possessing permeability to both glycerol and water. We have named the protein $\mathrm{Gla}_{\mathrm{Llac}}$, for glycerol facilitatoraquaporin of L. lactis.

E. coli uses glycerol as a carbon source for glycolysis and for lipid biogenesis. Glycerol enters the cytoplasm by passive diffusion across the lipid bilayer (Sweet et al., 1990) or by facilitative diffusion mediated by GlpF (Heller et al., 1980). The E. coli glycerol facilitator, GlpF, has been shown to selectively transport glycerol and not water or ions (Maurel et al., 1994). GlpF contributes directly to bacterial growth as illustrated by the complementation experiments presented in this paper. When expressed in E. coli, Gla $\mathrm{Llac}_{\mathrm{c}}$ can play a role in bacterial growth like E. coli GlpF. We have therefore analysed the transport of glycerol mediated by Gla both in bacteria and in Xenopus oocytes. We found that $\mathrm{Gla}_{\mathrm{Llac}}$ displays the same characteristics as E. coli GlpF 
for glycerol transport, allowing us to conclude that $\mathrm{Gla}_{\mathrm{Llac}}$ is a glycerol facilitator.

So far, AqpZ, the aquaporin of E. coli, is the only bacterial water channel which has been extensively functionally studied (Calamita et al., 1995, 1998; Delamarche et al., 1999; Borgnia et al., 1999b; Scheuring et al., 1999; Ringler et al., 1999; Calamita, 2000). Although puzzling questions on the physiological necessity of fast water transport in bacteria remain, it appears that aquaporins could be directly involved in cell proliferation (Calamita et al., 1998). This is supported by our observations in E. coli, in which two null mutations in $g l p F$ and $a q p Z$ obviated growth. Growth was partly restored when E. coli GlpF was expressed and was completely restored with the expression of $\mathrm{Gla}_{\mathrm{Llac}}$. This suggests that $\mathrm{Gla}_{\mathrm{Llac}}$ can mimic AqpZ function to restore growth in bacteria. Such complementation experiments using E. coli strain SK46 can be used to test the function of bacterial MIPs. We previously characterized bacterial aquaporins using cryoelectron microscopy and E. coli as an expression system (Delamarche et al., 1999; Rodriguez et al., 2000). In the present study we show that Gla Llac $_{\text {significantly }}$ mediates water fluxes. Moreover, the water channel properties of $\mathrm{Gla}_{\mathrm{Llac}}$ were demonstrated when the protein was expressed in Xenopus oocytes. The calculated $P_{\mathrm{f}}$ for Gla $\mathrm{Llac}_{\mathrm{Lac}}$ has the same magnitude as AqpZ. Moreover the low activation energy calculated for oocytes expressing $\mathrm{Gla}_{\mathrm{Llac}}$ corresponds to that of a water channel. Therefore $\mathrm{Gla}_{\mathrm{Llac}}$ is a mixed channel, like aquaglyceroporins described in mammals, and the first one to be characterized in bacteria. Unlike mammalian aquaglyceroporins (Kuriyama et al., 1997; Tsukagushi et al., 1998; Echevarria et al., 1996), $\mathrm{Gla}_{\mathrm{Llac}}$ imparts a high permeability to glycerol to the cell membrane.

Protein sequence alignments can be used to predict the function of an MIP (Froger et al., 1998; Delamarche, 2000). In Fig. 1, a high score between two sequences suggests that the two corresponding proteins have a similar function. For Gram-negative bacteria, the scores suggest that glycerol and water transport are assumed to occur independently by two distinct channels. We propose that Gram-positive bacteria contain a single MIP that possesses the two functions of glycerol facilitator and water channel. Recent studies on Bacillus subtilis, another Gram-positive bacterium, have confirmed this prediction (A. Froger \& C. Delamarche, unpublished). According to the key residues predicted to distinguish the functional subgroups of MIP (Froger et al., 1998), it can be noted that the sequences of the third group bears the signature of glycerol channels. Thus, it would be interesting to define other key residues or motifs that could determine the properties of mixed MIPs. For example, among residues that interact with glycerol in the GlpF channel (Fu et al., 2000), the proline residue at position 246 of E. coli GlpF is found in all the glycerol facilitator group defined in Fig. 1. Intriguingly, this proline is substituted by a glycine residue in all the sequences of the third group of putative mixed channels.
In mammalian aquaglyceroporins, this proline is also substituted by a leucine, alanine, methionine or phenylalanine.

The determination of the structure of GlpF has been a major factor in the elucidation of the mechanism of selective permeability for glycerol. However, the proposed mechanism for water transport by AQP1 still requires a higher resolution structure. Moreover, the molecular mechanism for mixed channels has still to be cleared up. Analysis of factors affecting the specificity of mixed channels conducted together with high resolution structural studies should provide some key answers to this phenomenon. In that way $\mathrm{Gla}_{\mathrm{Llac}}$ from L. lactis should be an interesting tool for solving this problem.

\section{ACKNOWLEDGEMENTS}

This work is dedicated to the memory of Professor Jean Gouranton (1934-1999), exemplary friend and scientist. We are very grateful to Michèle Nardi and Jean-Claude Gripon for providing pTil2, Winfred Boss for GD236, Giuseppe Calamita, Peter Agre and Erhard Bremer for SK46, Georgette Bonnec for technical assistance and Emmanuelle Guiot for photography.

\section{REFERENCES}

Agre, P., Bonhivers, M. \& Borgnia, M. J. (1998). The aquaporins, blueprints for cellular plumbing systems. J Biol Chem 273, 14659-14662.

Borgnia, M., Nielsen, S., Engel, A. \& Agre, P. (1999a). Cellular and molecular biology of the aquaporin water channels. Annu Rev Biochem 68, 425-458.

Borgnia, M. J., Kozono, D., Calamita, G., Maloney, P. C. \& Agre, P. (1999b). Functional reconstitution and characterization of AqpZ, the E. coli water channel protein. J Mol Biol 291, 1169-1179.

Calamita, G. (2000). The Escherichia coli aquaporin- $Z$ water channel. Mol Microbiol 37, 254-262.

Calamita, G., Bishai, W. R., Preston, G. M., Guggino, W. B. \& Agre, P. (1995). Molecular cloning and characterization of AqpZ, a water channel from Escherichia coli. J Biol Chem 270, 29063-29066.

Calamita, G., Kempf, B., Bonhivers, M., Bishai, W. R., Bremer, E. \& Agre, P. (1998). Regulation of the Escherichia coli water channel gene aqpZ. Proc Natl Acad Sci U S A 95, 3627-3631.

Delamarche, C. (2000). Color and graphic display (CGD): programs for multiple sequence alignment analysis in spreadsheet software. BioTechniques 29, 100-107.

Delamarche, C., Thomas, D., Rolland, J.-P., Froger, A., Gouranton, J., Svelto, M., Agre, P. \& Calamita, G. (1999). Visualization of AqpZ-mediated water permeability in Escherichia coli by cryoelectron microscopy. J Bacteriol 181, 4193-4197.

Devereux, J., Haeberli, P. \& Smithies, O. (1984). A comprehensive set of sequence analysis programs for the VAX. Nucleic Acids Res 12, 387-395.

Echevarria, M., Windhager, E. E., Tate, S. S. \& Frindt, G. (1994). Cloning and expression of AQP3, a water channel from the medullary collecting duct of rat kidney. Proc Natl Acad Sci U S A 91, 10997-11001.

Echevarria, M., Windhager, E. E. \& Frindt, G. (1996). Selectivity of the renal collecting duct water channel aquaporin-3. J Biol Chem 271, 25079-25082. 
Froger, A., Tallur, B., Thomas, D. \& Delamarche, C. (1998). Prediction of functional residues in water channels and related proteins. Protein Sci 7, 1458-1468.

Fu, D., Libson, A., Miercke, L. J. W., Weitzman, C., Nollert, P., Krucinski, J. \& Stroud, R. M. (2000). Structure of a glycerol conducting channel and the basis of its selectivity. Science $\mathbf{2 9 0}$, 481-486.

Heller, K. B., Lin, E. C. C. \& Wilson, T. H. (1980). Substrate specificity and transport properties of the glycerol facilitator of $E$. coli. J Bacteriol 144, 274-278.

Henikoff, S. \& Henikoff, G. J. (1992). Amino acid substitution matrices from protein blocks. Proc Natl Acad Sci USA 89, 10915-10919.

Hohmann, S., Bill, R. M., Kayingo, G. \& Prior, B. (2000). Microbial MIP channels. Trends Microbiol 8, 33-38.

Ishibashi, K. \& Sasaki, S. (1998). The dichotomy of MIP family suggests two separate origins of water channels. News Physiol Sci 13, 137-142.

Ishibashi, K., Sasaki, S., Fushimi, K. \& 8 others (1994). Molecular cloning and expression of a member of the aquaporin family with permeability to glycerol and urea in addition to water expressed at the basolateral membrane of kidney collecting duct cells. Proc Natl Acad Sci US A 91, 6269-6273.

Ishibashi, K., Kuwahara, M., Gu, Y., Kageyama, Y., Tohsaka, A., Suzuki, F., Marumo, F. \& Sasaki, S. (1997). Cloning and functional expression of a new water channel abundantly expressed in the testis permeable to water, glycerol, and urea. J Biol Chem 272, 20782-20786.

Kuriyama, H., Kawamoto, S., Ishida, N., Ohno, I., Mita, S., Matsuzawa, Y., Matsubara, K. \& Okubo, K. (1997). Molecular cloning and expression of a novel human aquaporin from adipose tissue with glycerol permeability. Biochem Biophys Res Commun 241, 53-58.

Lagrée, V., Froger, A., Deschamps, S., Pellerin, I., Delamarche, C., Bonnec, G., Gouranton, J., Thomas, D. \& Hubert, J. F. (1998). Oligomerisation state of water channels and glycerol facilitators: involvement of the loop E. J Biol Chem 273, 33949-33953.

Lagrée, V., Froger, A., Deschamps, S., Hubert, J. F., Delamarche, C., Bonnec, G., Thomas, D., Gouranton, J. \& Pellerin, I. (1999). Switch from an aquaporin to a glycerol channel by two aminoacids substitution. J Biol Chem 274, 6817-6819.

Le Cahérec, F., Deschamps, S., Delamarche, C., Pellerin, I., Bonnec, G., Guillam, M. T., Thomas, D., Gouranton, J. \& Hubert, J. F. (1996). Molecular cloning and characterization of an insect aquaporin. Functional comparison with aquaporin-1. Eur $J$ Biochem 241, 707-715.

Ma, T., Frigeri, A., Hasegawa, H. \& Verkman, A. S. (1994). Cloning of a water channel homolog expressed in brain meningeal cells and kidney collecting duct that functions as a stilbene-sensitive glycerol transporter. J Biol Chem 269, 21845-21849.

Maurel, C. (1997). Aquaporins and water permeability of plant membranes. Annu Rev Physiol Plant Mol Biol 48, 399-429.

Maurel, C., Reizer, J., Schroeder, J. I., Chrispeels, L. J. \& Saier, M. H., Jr (1994). Functional characterization of the Escherichia coli glycerol facilitator, GlpF, in Xenopus oocytes. J Biol Chem 269, 11869-11872.
Mayo, B., Kok, J., Venema, K., Bockelmann, W., Teuber, M., Reinke, H. \& Venema, G. (1991). Molecular cloning and sequence analysis of the X-prolyl dipeptidyl aminopeptidase gene from Lactococcus lactis subsp. cremoris. Appl Environ Microbiol 57, 38-44.

Meselson, M. \& Yuan, R. (1968). DNA restriction enzyme from $E$. coli. Nature 217, 1110-1114.

Messing, J., Crea, R. \& Seeburg, P. H. (1981). A system for shotgun DNA sequencing. Nucleic Acids Res 24, 309-321.

Murata, K., Mitsuoka, K., Hirai, T., Walz, T., Agre, P., Heymann, B., Engel, A. \& Fujiyoshi, Y. (2000). Structural determinants of water permeation through aquaporin-1. Nature 407, 599-605.

Nardi, M., Chopin, M. C., Chopin, A., Cals, M. M. \& Gripon, J. C. (1991). Cloning and DNA sequence analysis of an X-prolyl dipeptidyl aminopeptidase gene from Lactococcus lactis subsp. lactis NCDO 763. Appl Environ Microbiol 57, 45-50.

Preston, G. M., Carroll, T. P., Guggino, W. B. \& Agre, P. (1992). Appearance of water channels in Xenopus oocytes expressing red cell CHIP28 protein. Science 256, 385-387.

Ren, G., Cheng, A., Reddy, V., Melnyk, P. \& Mitra, A. K (2000). Three-dimensional fold of human AQP1 water channel determined at $4 \AA$ resolution by electron crystallography of twodimensional crystals embedded in ice. J Mol Biol 301, 369-387.

Ringler, P., Borgnia, M. J., Stahlberg, H., Maloney, P. C., Agre, P. \& Engel, A. (1999). Structure of the water channel AqpZ from Escherichia coli revealed by electron crystallography. J Mol Biol 291, 1181-1190.

Rodriguez, M. C., Froger, A., Rolland, J.-P., Thomas, D., Agüero, J., Delamarche, C. \& Garcia Lobo, J. M. (2000). Characterization of AqpX, a water channel protein from the pathogenic bacteria Brucella abortus. Microbiology 146, 3251-3257.

Sambrook, J., Fritsch, E. F. \& Maniatis, T. (1989). Molecular Cloning: a Laboratory Manual, 2nd edn. Cold Spring Harbor, NY : Cold Spring Harbor Laboratory.

Scheuring, S., Ringler, P., Borgnia, M., Stahlberg, H., Müller, D. J., Agre, P. \& Engel, A. (1999). High resolution AFM topographs of the Escherichia coli water channel aquaporin Z. EMBO J 18, 4981-4987.

Sweet, G., Gandor, C., Voegele, R., Wittekindt, N., Beuerle, J., Truniger, V., Lin, E. C. \& Boos, W. (1990). Glycerol facilitator of Escherichia coli: cloning of $g l p F$ and identification of the $g l p F$ product. J Bacteriol 172, 424-430.

Thompson, J. D., Higgins, D. G. \& Gibson, T. J. (1994). CLUSTAL w : improving the sensitivity of progressive multiple sequence alignment through sequence weighting, position-specific gap penalties and weight matrix choice. Nucleic Acids Res 22, 4673-4680.

Tsukagushi, H., Shayakul, C., Berger, U. V., Mackensie, B., Devidas, S., Guggino, W. B., Van Hoek, A. N. \& Hediger, M. A. (1998). Molecular characterization of a broad selectivity neutral solute channel. J Biol Chem 273, 24737-24743.

Yanisch-Perron, C., Vieira, J. \& Messing, J. (1985). Improved M13 phage cloning vectors and host strains: nucleotide sequences of the M13mp18 and pUC19 vectors. Gene 33, 103-119.

Received 11 October 2000; revised 20 December 2000; accepted 2 January 2001. 